used to a greater extent for the accurate location of atomic centres rather than the method of steepest descents. Thirdly, Lipson and Taylor's development of optical methods for viewing molecular transforms and for the determination of phases has given a new turn to our concepts of structure determination. Nevertheless, these recent developments do not in any way diminish the usefulness of this book.

The second part of the book deals with methods of calculating Fourier series and structure factors. There is a full description of the Beevers-Lipson method, and brief references are made to other electro-mechanical aids, of which the Hollerith punched-card technique has come to be widely used.

The book as a whole is well produced, well indexed and well referenced. It is to be hoped that Prof. Nowacki will bring out a second edition in which are incorporated the more recent advances, thus adding to the merit of an already useful book which can be fully recommended.

C. H. CARLisle

\section{PHYSICS MONOGRAPHS FOR STUDENTS}

Fundamentals of Thermometry

By J. A. Hall. Pp. 48.

Practical Thermometry

By J. A. Hall. Pp. 51 .

Soft Magnetic Materials used in Industry

By A. E. DeBarr. Pp. 62.

The Magnetic Circuit

Powder Cores, Ferrites, Permanent Magnet Materials, and Miscellaneous Magnetic Materials. By A. E. DeBarr. Pp. 62. (Monographs for Students.) London: Institute of Physics, 1953. 5s. each.

7 HE Institute of Physics by its various publications, particularly the Physies in Industry series of monographs and the monthly journal, the British Journal of Applied Physics, has greatly advanced the study and development of applied physics and provides the industrial physicist and research worker with up-to-date factual information. The proper training of applied physicists, a matter of paramount importance, has also occupied the attention of the Institute, and it issues National Certificates in applied physics jointly with the Ministry of Education and the Scottish Education Department. However, the usual text-books on physics are not primarily concerned with the practical applications and with instruments, and thus the Institute has started to publish a new series of "Monographs for Students" which have been specially written for general reading by students attending courses for the Higher National Certificate in applied physics; these books constitute a valuable and important contribution to the literature of applied physies, and a stimulus and aid to the student.

The first four volumes in this series are remarkable for their excellence in content and production. The graphs are particularly clear and easy to read, though some diagrams have suffered from over-reduction. "Fundamentals of Thermometry" and "Practical Thermometry" are companion volumes: in the former attention is concentrated on the International Temperature Scale, and in the latter the instruments and techniques described are largely those recommended by, or used at, the National Physical
Laboratory, where the author is a senior principal scientific officer and is actively engaged in the testing and development of temperature-measuring instruments. "Soft Magnetic Materials used in Industry" and "The Magnetic Circuit" are also companion volumes, and, in case the reader may be misled by these titles, it is perhaps well to add that the physical basis of, and introduction to, magnetic properties is given in the first of these two monographs, while in the other are details of powder cores, ferrites and other magnet materials. The domain theory of ferromagnetism, antiferromagnetism and ferrimagnetism all receive adequate treatment.

The monographs are short but handy booklets in stiff paper covers; they should have a wide circulation.

S. WeINTROUB

\section{D.C. ANALOGUE COMPUTERS}

Electronic Analog Computers (D-C Analog Computers)

By Dr. Granino A. Korn and Theresa M. Korn. Pp. $\mathrm{xv}+378$. (London: McGraw-Hill Publishing Co., Ltd., 1952.) 59s. $6 d$.

THIS book is concerned with electronic analogue computers of one class only, namely, those in which the variables are represented by voltages and in which the circuits are direct-coupled throughout. The authors are primarily concerned with the use of such machines for solving sets of ordinary differential equations in which time can be used for representing the independent variable. There is a section dealing with machines for solving sets of simultaneous algebraic equations, but this subject is not dealt with at length.

The authors are much too concerned with practical details of design to attempt to define the field in which D.C. analogue computers are of use, although they wax enthusiastic on p. 3 about a computer wired up from scrap parts on a 'bread-board' in two hours at negligible cost and ready to furnish needed information with fair accuracy. But it is clear from the book that the authors have been primarily concerned with the use of analogue computers in aircraft design, both for investigating the behaviour of servo systems, non-linear damped oscillators, etc., and also as simulators, for example, in the testing of autopilots when a computer can be used to simulate the behaviour of an aircraft. In these applications the main drawback of analogue computers-poor and uncertain accuracy which falls almost to nothing when the magnitude of the variable considered changes by a large factor-is not greatly in evidence. This is partly because the results are interpreted by engineers who understand the working of the computer and know when the results given are likely to be trustworthy. I am not sure whether the authors would agree that analogue computers are less useful for dealing with differential equations which arise in more mathematical contexts-for example, in theoretical physics.

The greater part of the book is concerned with theoretical and practical aspects of the design of D.c. amplifiers, integrators, differentiators, multipliers, function generators and other computing circuits. This part of the book is admirably practical and should be of use to anyone concerned with the design of electronic devices which include computing elements. The section on the choice of scale factors should similarly be of interest to users of analogue computers.
M. V. WILKES 